\title{
Predictable Dynamics in the Small Stock Premium
}

\author{
Valeriy Zakamulin \\ Department of Economics and Finance, University of Agder, Service Box 422, 4604 Kristiansand, Norway
}

Correspondence should be addressed to Valeriy Zakamulin; valeri.zakamouline@uia.no

Received 9 November 2013; Accepted 14 January 2014; Published 20 February 2014

Academic Editor: Thanasis Stengos

Copyright (C) 2014 Valeriy Zakamulin. This is an open access article distributed under the Creative Commons Attribution License, which permits unrestricted use, distribution, and reproduction in any medium, provided the original work is properly cited.

\begin{abstract}
We start this paper by providing a detailed study of how the mean monthly return on the Small-Minus-Big (SMB) Fama-French factor is affected by the January effect and the stock market return during the preceding month and preceding calendar year. We then proceed to building a predictive model for the monthly SMB factor return that incorporates the January effect and the dependence on both the market return during the preceding month and preceding calendar year. Our findings suggest that a positive small stock premium appears mainly during the years following the years with a negative return on the market as the result of a delayed and stronger reaction of small stocks to good news and a stronger January effect. We also argue that the January effect constitutes a much lesser part of the size effect than it was previously supposed.
\end{abstract}

\section{Introduction}

Since the publication of the studies by Banz [1] and Reinganum [2], numerous papers have documented that small size firms earn higher risk-adjusted stock returns than large firms (this phenomenon is often called the "size effect."). Several competing explanations for what gives rise to the size premium have been proposed. A majority of papers contend that the size premium is the investors compensation for bearing a greater systematic risk (see Chan et al. [3], Fama and French [4], and Vassalou and Xing [5]). The non-risk-based explanations include lesser liquidity of small stocks (see Stoll and Whaley [6] and Pástor and Stambaugh [7]); survivorship bias (see Kothari et al. [8] and Shumway and Warther [9]); and delayed price response (see Hou and Moskowitz [10]). In contrast to the rational explanations for the source of the small size premium, Lo and MacKinlay [11] and Black [12] argue that the size effect can be a result of data mining.

Besides the heated debate on the source of the size premium, there are two puzzles in the size effect anomaly. First, several studies demonstrate that from 50 to $100 \%$ of the size effect in the USA can be attributed to superior returns of small size firms in January (see Keim [13], Brown et al. [14], Lamoureux and Sanger [15], Daniel and Titman [16], and van Dijk [17]). In this regard, one usually points out that the common weakness of all above mentioned potential rational explanations for the size effect is their apparent inability to account for the January effect. To explain the January effect, there have been proposed two alternative hypothesis: the "tax-loss selling" hypothesis and the "window dressing" hypothesis (see Ritter [18]). (The "tax-loss selling" hypothesis says that small investors appear to sell stocks that have declined in price during a year in order to realize tax losses. However, they appear to wait until January to reinvest in small stocks because January buying can be augmented by cash infusions from year-end bonuses or from the sales of large-cap stocks on which long-term capital gains are being realized. The "window dressing" hypothesis says that in order to present sound portfolio holdings, institutional investors have an incentive to buy winners and sell losers at the end of a year. Early in January, they rebalance their portfolios in favor of more speculative securities.) Second, many studies report that the size premium is not robust but appeared only in some specific periods. For example, the size premium was present over the period 1964-1981, but nonexistent over the period 1982-2000 (see Eleswarapu and Reinganum [19], Dichev [20], Amihud [21], Malkiel [22], and Dimson and Marsh [23]). To explain the time variations in the size premium, Chan et al. 
[3], Vassalou and Xing [5], and Baker and Wurgler [24] advocate that the size effect appears in adverse economic conditions. Yet the appearance of the size premium in bad economic times is difficult to reconcile with either the delayed price response hypothesis or the evidence that the most part of the size premium can be attributed to the January effect.

Recently Zakamulin [25] counters the data mining argument and provides evidence that the small stock premium is predictable both in-sample and out-of-sample through the use of a set of lagged macroeconomic variables. In particular, Zakamulin documents that the stock market return is a robust predictor of the size premium at the monthly and annual sampling frequencies. The puzzle in these findings is that whereas at the monthly frequency a positive return on the stock market predicts a positive size premium (which is consistent with the price delay hypothesis), at the annual frequency it is a negative return on the stock market that predicts a positive size premium (which is largely consistent with the evidence that the size premium appears in adverse economic conditions).

The goal of this paper is to suggest a resolution of the above mentioned puzzles in the small stock premium and shed additional light on what gives rise to the size premium. The paper presents several contributions to the existing literature. The first contribution is to provide a detailed study of the unconditional and conditional mean monthly returns on the Small-Minus-Big (SMB) Fama-French factor. This is done for all months together, non-January months and January months. We confirm that if one considers the unconditional mean monthly returns on the SMB factor for January versus non-January months, then one is tempted to conclude that the size effect is almost entirely due to higher returns on small stocks in January. Yet, the study of the mean monthly returns conditional on the sign of the market return during the preceding month allows us to conclude that the size premium in non-January months changes its sign depending on the sign of the market return. In particular, a positive size premium tends to be generated during the months following the months in which the return on the market was positive. In contrast, a negative size premium tends to be generated during the months following the months in which the return on the market was negative. We find that the January effect persists regardless of the sign of the market return in December.

Further, the study of the mean monthly SMB factor returns conditional on the sign of the market return during the preceding calendar year allows us to conclude that a positive size premium is mainly generated during the years following the years in which the return on the market was negative. In contrast, during the years following the years in which the return on the market was positive, on average there is virtually no size premium. It is worth noting that this evidence allows us to explain the puzzling absence of the size effect over the period 1982-2000. The explanation is based on the fact that this period was the years of prolonged good times of economy and a long bull market in the stocks. Indeed, during these 19 years the annual return on the market was negative only once in 1990. Moreover, from December 1982 to March 2001, the NBER's Business Cycle Dating Committee identified only one relatively short recession over the period from July 1990 to March 1991. The Dot-Com bubble crash marked the end of the long good times. As a result, the return on the SMB factor was mainly positive over the period 20012011.

In addition, we find that the January effect is larger after years with a negative return on the market than after years with a positive return on the market. This provides an additional support for either the "tax-loss selling" hypothesis or the "window dressing" hypothesis to explain the January effect. Observe that either of the two hypotheses predicts a stronger January effect after years when the stock market return was negative. This is because when the market goes down during a year, the majority of stocks decline in price. Since the small cap stocks have larger negative betas than the large cap stocks (see Eun et al. [26]), in a falling market the prices of small stocks decrease greater than the prices of large stocks. This causes larger small stock selling in December to either realize tax losses or to eliminate embarrassing losers from portfolios managed by professional investors, with consequent larger small stock buying in January.

Lastly, we study the mean monthly returns on the SMB factor conditional on the signs of both the market return during the preceding calendar year and during the preceding month. We find that a negative size premium tends to be generated during the months following the months in which the return on the market was negative regardless of the sign of the market return during the preceding calendar year. Furthermore, a positive size premium tends to be generated during the months following the months in which the return on the market was positive. Yet, in this case the magnitude of the size premium depends heavily on the sign of the market return during the preceding calendar year. Specifically, the size premium tends to be substantially higher when the return on the market during the preceding calendar year was negative.

The second contribution of this paper is to build a predictive model for the monthly SMB factor return that incorporates the January effect and the dependence on both the market return during the preceding month and preceding calendar year. We build such a model stepwise by comparing some alternative model specifications. It turns out that our predictive model is able to reconcile the delayed price response hypothesis of Hou and Moskowitz [10] and the evidence that the size premium tends to appear in adverse economic conditions. We find that the monthly SMB factor return responds asymmetrically to negative and positive returns on the market during the preceding month, which is consistent with the findings presented by Mcqueen et al. [27]. These authors document that the small cap stocks delay with response to good news but not to bad news. In order to reconcile the dynamics of the size premium at the monthly and annual frequencies, we need to assume that the annual dynamics influences the monthly dynamics. As a result, the predictive model built in this paper represents a refinement of the directionally asymmetry discovered by Mcqueen et al. [27]. We document a new empirical characteristic of this directional asymmetry: dependence on the sign of the market 
return during the preceding calendar year. In particular, we found that after years with positive return on the market the small cap stocks react quickly to negative news and with a delay to good news. Yet the delayed reaction to good news is not especially strong such that the generated small stock premium during non-January months is nonexistent or rather negative. In contrast, after years with negative return on the market the small cap stocks delay with a reaction to good news as well, but in this case the reaction is much stronger such that the generated small stock premium is positive. It is worth noting that these findings also suggest a need for asset pricing models that allow not only nonlinear behavior that depends on the sign of a variable but also behavior that depends on the value of a variable sampled at a different frequency.

It should be emphasized, however, that the predictive model for the monthly SMB factor return is built using in-sample predictive regressions. It is widely known now that significant in-sample evidence of predictability does not guarantee significant out-of-sample predictability. As a matter of fact, Welch and Goyal [28] demonstrate that the stock market is generally not predictable out-of-sample. Therefore, the predictive model for the small stock premium is largely meant to "explain" the dynamics of the monthly SMB factor return in the past. We also find evidence that the predictability of the size effect has been diminishing through time. This might indicate that the stock market efficiency has been increasing through time and the size effect predictability may vanish in the future.

The third and final contribution of this paper is to reconsider how much of the size effect can be attributed to the January effect. According to the previous estimates based on the study of the unconditional mean monthly returns on the SMB factor, researchers find that up to $100 \%$ of the size effect can be attributed to the January effect. Using two different approaches we argue that the January effect constitutes a much lesser part of the size effect than it was previously suggested. Specifically, we estimate that only about $23-24 \%$ of the size effect can be attributed to the January effect (and, consequently, 76-77\% of the size effect can be attributed to the delayed price response). In brief, the reason for the spurious absence of the size effect during non-January months in unconditional returns is the cyclical variations in the size premium. In particular, if we focus on nonJanuary returns only, the periods with a positive size premium tend to be counterbalanced by periods with a negative size premium. As a result, the average (unconditional) size premium during non-January months becomes small and statistically insignificant. Consequently, we conclude that the role of the January effect in the size effect seems to be overstated and there is no substantial conflict between, for example, a risk-based explanation for the size effect and the January effect. Yet our findings suggest that a positive small stock premium appears mainly during the years following the years with a negative return on the market as the result of a delayed and stronger reaction of small stocks to good news and a stronger January effect.

The rest of the paper is organized as follows. Section 2 presents the data and briefly reviews the evidence that the stock market return is able to predict the size premium at both the monthly and annual frequencies. In Section 3, we perform a detailed study of the unconditional and conditional mean monthly returns on the SMB factor. In Section 4, we build the predictive model for the monthly SMB factor return. In Section 5, we reconsider how much of the size effect can be attributed to the January effect. Section 6 concludes the paper.

\section{Preliminaries}

2.1. Data. Our sample period begins in January 1927 and ends in December 2011, giving a total of 1020 monthly observations and 85 annual observations. The monthly returns on the stock market and SMB factor, denoted by $\mathrm{MKT}_{t}^{m}$ and $\mathrm{SMB}_{t}^{m}$, respectively, as well as annual returns on the stock market and $\mathrm{SMB}$ factor, denoted by $\mathrm{MKT}_{T}^{a}$ and $\mathrm{SMB}_{T}^{a}$, respectively, are obtained from the data library of Kenneth French (See http:// mba.tuck.dartmouth.edu/pages/faculty/ken.french/data_library.html).

In particular, as the stock market return we use the return on the value-weighted portfolio consisting of the top quintile $(20 \%)$ of all firms in the aggregate stock market sorted according to their market capitalizations. (Here, the aggregate stock market consists of all NYSE, AMEX, and NASDAQ stocks for which there are market equity data. The size-sorted quintile portfolios are constructed at the end of each June using the June market capitalization and NYSE breakpoints.) Note that by construction our stock market return is the return on the large capitalization stocks. The number of stocks in the portfolio varies from 100 to 500 . Thus, our return on the stock market roughly corresponds to the return on the Standard and Poor's Composite Stock Price Index. This specific choice for the stock market return can be justified on two grounds. First, since we use only large cap stocks, our stock market return is not influenced by either the small size effect or the survivorship bias. Second, it is documented in the literature (see, e.g., Lo and MacKinlay [29] and Mcqueen et al. [27]) that large cap stocks lead small cap stocks over horizons from one week to one month. Therefore, the return on the large cap stocks seems to be a potentially better predictor of the return on the SMB factor than the return on the aggregate stock market.

The SMB factor returns are constructed using the 6 Fama-French value-weighted portfolios formed on size and book-to-market. These portfolios, which are formed monthly, are the intersections of 2 portfolios formed on size and 3 portfolios formed on the ratio of book equity to market equity. For a complete description of the construction of the SMB factor returns, see Fama and French [4].

\subsection{Annual Market Return as a Predictor of the SMB Factor} Return. Ferson and Harvey [30] and Cooper et al. [31] estimate, among other things, a predictive regression for the SMB Fama-French factor using a set of lagged economy-wide predictive variables. The predictive regression was estimated using monthly data only. The findings in these papers suggest that some lagged macroeconomic variables can predict the $\mathrm{SMB}$ factor return. In particular, these authors find that 
a positive return on the stock market predicts a positive size premium. Zakamulin [25] demonstrates that it is possible to forecast the SMB factor return not only at the monthly frequency but also over longer time horizons up to one year. Zakamulin finds that the stock market return is a robust predictor of the size premium at the monthly and annual sampling frequencies. What is interesting, though, is that at the annual frequency it is a negative return on the stock market that predicts a positive SMB factor return.

Figure 1 provides the readers with an elevated bird's-eye view on the joint dynamics of the small stock premium and the stock market return. In particular, this figure visualizes the joint annual dynamics of the detrended log of the stock market index and the detrended log of the compounded SMB factor return. Apparently, the periods of above average returns on the SMB factor tend to comove with the periods of below average returns on the stock market. In order to predict the SMB factor return, Zakamulin [25] uses a standard linear predictive regression. Alternatively, in order to demonstrate that the stock market return can predict the SMB factor return, one can employ the following Linear Probability Model for Binary Response (here we focus only on the annual data frequency):

$$
\operatorname{Prob}\left(\mathrm{SMB}_{T}^{a}>0 \mid \delta_{A}\right)=\pi_{0}+\pi_{1} \delta_{A}+\varepsilon_{t},
$$

where $\delta_{A}$ is a binary indicator (dummy variable) that takes the value of 1 when the return on the market during the preceding calendar year is negative and zero otherwise,

$$
\delta_{A}= \begin{cases}1 & \text { if } \mathrm{MKT}_{T-1}^{a} \leq 0 \\ 0 & \text { if } \mathrm{MKT}_{T-1}^{a}>0\end{cases}
$$

$\operatorname{Prob}\left(\mathrm{SMB}_{T}^{a}>0 \mid \delta_{A}\right)$ is a probability that the annual return on the SMB factor will be positive conditional on the sign of the market return during the preceding year. In particular, when the sign of the market return during the preceding year is positive, the probability that the annual return on the $\mathrm{SMB}$ factor will be positive is given by $\operatorname{Prob}\left(\mathrm{SMB}_{T}^{a}>0\right.$ | $\left.\mathrm{MKT}_{T-1}^{a}>0\right)=\pi_{0}$. In contrast, when the sign of the market return during the preceding year is negative, the probability that the annual return on the SMB factor will be positive is given by $\operatorname{Prob}\left(\mathrm{SMB}_{T}^{a}>0 \mid \mathrm{MKT}_{T-1}^{a} \leq 0\right)=\pi_{0}+\pi_{1}$. That is, $\pi_{1}$ is the change in the probability that the annual return on the SMB factor will be positive when the sign of the market return changes from positive to negative. The results of the estimate of (1) using OLS produce the following estimates: $\pi_{0}=0.51$ and $\pi_{1}=0.21$. The bootstrap estimates of the $P$ values (based on performing 10,000 resamples using the method of Efron [32]) for the intercept and slope suggest that $\pi_{0}$ is statistically significantly different from zero at the $1 \%$ level, whereas $\pi_{1}$ is statistically significantly different from zero at the 5\% level. This allows us to reject the null hypothesis that the sign of the market return during a year has no influence on the sign of the SMB factor return during the subsequent year. Thus, the linear probability model suggests that if during a year the return on the market is positive, then there is about a $50 \%$ chance that the SMB factor return during the subsequent year will be positive. In contrast, if during a year the return on

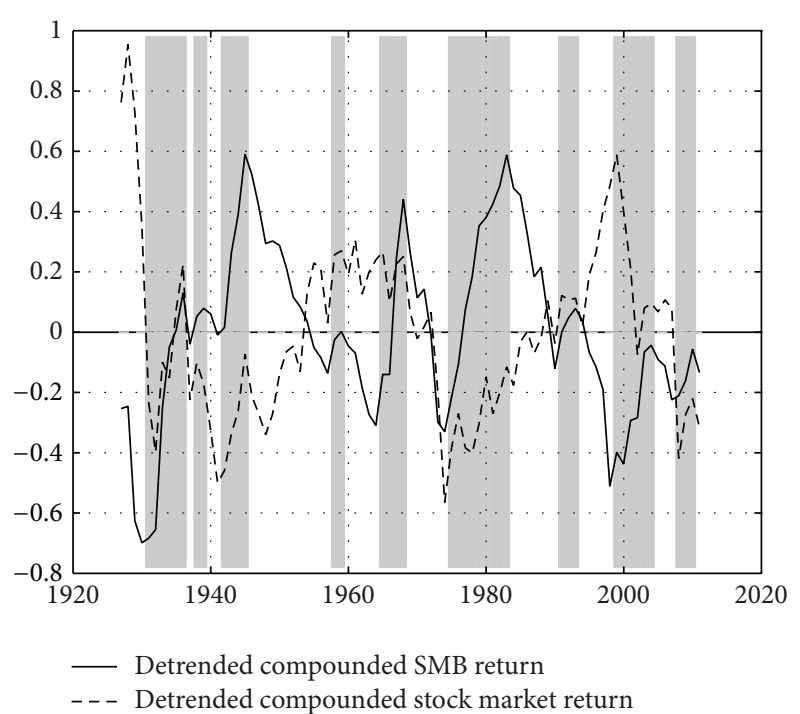

FIGURE 1: Dynamics of the detrended compounded log of the SMB factor return versus the dynamics of the detrended compounded $\log$ of the stock market return. To make this plot, we use annual data. Detrending is performed using the Hodrick-Prescott filter. The shaded areas highlight the long periods of mainly positive returns on the SMB factor.

TABLE 1: The unconditional mean monthly returns on the SMB factor. The value in the brackets reports the $P$ value of the $t$-test for zero mean. Bold text indicates mean monthly returns that are statistically significantly different from zero at the $5 \%$ level.

\begin{tabular}{lc}
\hline Month(s) & Mean return \\
\hline All together & $\mathbf{0 . 2 5}(0.02)$ \\
Non-January & $0.06(0.56)$ \\
January & $\mathbf{2 . 3 2}(0.00)$ \\
\hline
\end{tabular}

the market is negative, then the probability that the SMB factor return during the subsequent year will be positive increases to about $70 \%$.

\section{Studying Conditional Mean Returns on the SMB Factor}

3.1. Unconditional Mean Returns. In this subsection, we investigate the unconditional mean monthly returns on the SMB factor. Table 1 reports the estimated mean monthly returns $E\left[\mathrm{SMB}_{t}^{m}\right]$ (together with the $P$ values of the $t$-test for zero mean) for all months together, non-January months, and January months. The results indicate that the unconditional mean monthly return for all months together amounts to $0.25 \%$ and is statistically significantly different from zero at the $2 \%$ level. Yet, if we consider the unconditional mean monthly returns for January versus non-January months, then we conclude that the size effect is almost entirely due to higher returns on small stocks in January. In particular, the mean SMB factor return in January months amounts to $2.32 \%$ and is highly statistically significantly different from zero, whereas the mean SMB factor return in non-January 
months amounts to $0.06 \%$ and is statistically insignificantly different from zero.

3.2. Conditional Mean Returns. First, we investigate the mean monthly returns on the SMB factor conditional on the sign of the market return during the preceding month. Specifically, we estimate $E\left[\mathrm{SMB}_{t}^{m} \mid \mathrm{MKT}_{t-1}^{m} \leq 0\right]$ and $E\left[\mathrm{SMB}_{t}^{m}\right.$ | $\mathrm{MKT}_{t-1}^{m}>0$ ], where $t-1$ denotes the preceding month, for all months together, non-January months, and January months. Table 2 reports the estimated conditional mean monthly returns on the SMB factor and the values of the $t$-statistics of the hypothesis test for equal conditional means (together with the $P$ values). These results suggest that the mean monthly return on the $\mathrm{SMB}$ factor conditional on $\mathrm{MKT}_{t-1}^{m}>0$ is statistically significantly positive for all months together and non-January months. In contrast, the mean monthly return on the SMB factor conditional on $\mathrm{MKT}_{t-1}^{m} \leq 0$ is statistically significantly negative for all months together and non-January months. The January effect persists regardless of the sign of the market return in December. This evidence allows us to conclude that the size premium in non-January months changes its sign depending on the sign of the market return during the preceding month. In particular, a positive size premium tends to be generated during the months following the months in which the return on the market was positive. In contrast, a negative size premium tends to be generated during the months following the months in which the return on the market was negative.

Secondly, we study the mean monthly returns on the SMB factor conditional on the sign of the market return during the preceding calendar year. Specifically, we estimate $E\left[\mathrm{SMB}_{t}^{m} \mid \mathrm{MKT}_{T-1}^{a} \leq 0\right]$ and $E\left[\mathrm{SMB}_{t}^{m} \mid \mathrm{MKT}_{T-1}^{a}>\right.$ 0 ], where $T-1$ denotes the preceding calendar year, for all months together, non-January months, and each month of the year. Table 3 reports the estimated conditional mean monthly returns on the SMB factor and the values of the $t$ statistics of the hypothesis test for equal conditional means (together with the $P$ values). These results reveal that for all months together, non-January months, and January months, the mean monthly return on the SMB factor conditional on $\mathrm{MKT}_{T-1}^{a} \leq 0$ is statistically significantly higher than the mean monthly return on the SMB factor conditional on $\mathrm{MKT}_{T-1}^{a}>$ 0 . This evidence allows us to conclude that a positive size premium is mainly generated during the years following the years in which the return on the market was negative. In contrast, during the years following the years in which the return on the market was positive, on average there is virtually no size premium.

Lastly, we investigate the mean monthly returns on the SMB factor conditional on the signs of both the market return during the preceding calendar year and during the preceding month. Specifically, we estimate $E\left[\mathrm{SMB}_{t}^{m} \mid \mathrm{MKT}_{T-1}^{a} \leq\right.$ $\left.0, \mathrm{MKT}_{t-1}^{m} \leq 0\right], E\left[\mathrm{SMB}_{t}^{m} \mid \mathrm{MKT}_{T-1}^{a} \leq 0, \mathrm{MKT}_{t-1}^{m}>0\right]$, $E\left[\mathrm{SMB}_{t}^{m} \mid \mathrm{MKT}_{T-1}^{a}>0, \mathrm{MKT}_{t-1}^{m} \leq 0\right]$, and $E\left[\mathrm{SMB}_{t}^{m}\right.$ | $\mathrm{MKT}_{T-1}^{a}>0, \mathrm{MKT}_{t-1}^{m}>0$ ] for all months together, nonJanuary months, and January months. Table 4 reports the estimated conditional mean monthly returns on the SMB factor (together with the $P$ values of the $t$-test for zero mean).
TABLE 2: The mean monthly returns on the SMB factor conditional on the sign of the market return during the preceding month. The means are given in percents. The value in the brackets reports the $P$ value of the (two-tailed) $t$-test for zero mean. The $t$-test for equal means reports the value of the $t$-statistics of the hypothesis test for equal conditional means against the alternative that the mean conditional on $\mathrm{MKT}_{t-1}^{m}>0$ is greater than the mean conditional on $\mathrm{MKT}_{t-1}^{m} \leq 0$. The value in the brackets reports the $P$ value of the (one-tailed) test for equal means. Bold text indicates values that are statistically significant at the $5 \%$ level.

\begin{tabular}{lccc}
\hline \multirow{2}{*}{ Month(s) } & \multicolumn{2}{c}{ Mean return conditional on } & $\begin{array}{c}t \text {-test for equal } \\
\text { means }\end{array}$ \\
& $\mathrm{MKT}_{t-1}^{m} \leq 0$ & $\mathrm{MKT}_{t-1}^{m}>0$ & $\mathbf{0 . 6 9}(0.00)$ \\
All together & $\mathbf{- 0 . 4 5}(0.01)$ & $\mathbf{0 . 0 0 0 )}$ \\
Non-January & $-\mathbf{0 . 6 4}(0.00)$ & $\mathbf{0 . 5 3}(0.00)$ & $\mathbf{5 . 3 9}(0.00)$ \\
January & $\mathbf{3 . 0 1}(0.00)$ & $\mathbf{2 . 1 0}(0.00)$ & $-1.04(0.16)$ \\
\hline
\end{tabular}

TABLE 3: The mean monthly returns on the SMB factor conditional on the sign of the market return during the preceding calendar year. The means are given in percents. The value in the brackets reports the $P$ value of the (two-tailed) $t$-test for zero mean. The $t$-test for equal means reports the value of the $t$-statistics of the hypothesis test for equal conditional means against the alternative that the mean conditional on $\mathrm{MKT}_{T-1}^{a} \leq 0$ is greater than the mean conditional on $\mathrm{MKT}_{T-1}^{a}>0$. The value in the brackets reports the $P$ value of the (one-tailed) test for equal means. Bold text indicates values that are statistically significant at the $5 \%$ level.

\begin{tabular}{lccc}
\hline \multirow{2}{*}{ Month(s) } & \multicolumn{2}{c}{ Mean return conditional on } & $\begin{array}{c}t \text {-test for equal } \\
\text { means }\end{array}$ \\
\hline $\mathrm{MKT}_{T-1}^{a} \leq 0$ & $\mathrm{MKT}_{T-1}^{a}>0$ & $\mathbf{2 . 3 9}(0.01)$ \\
All together & $\mathbf{0 . 7 7}(0.00)$ & $0.08(0.45)$ & $\mathbf{1 . 9 3}(0.03)$ \\
Non-January & $0.49(0.07)$ & $-0.08(0.48)$ & $\mathbf{2 . 3 1}(0.02)$ \\
January & $\mathbf{3 . 7 7}(0.00)$ & $\mathbf{1 . 8 3}(0.00)$ & \\
\hline
\end{tabular}

Table 5 reports the values of the $t$-statistics (together with the $P$ values) of the pairwise hypothesis test (two-sample twotailed $t$-test) for equal conditional mean monthly returns on the SMB factor. In particular, we test the hypothesis that, for example, $E\left[\mathrm{SMB}_{t}^{m} \mid \mathrm{MKT}_{T-1}^{a} \leq 0, \mathrm{MKT}_{t-1}^{m} \leq 0\right]$ is statistically significantly different from $E\left[\mathrm{SMB}_{t}^{m} \mid \mathrm{MKT}_{T-1}^{a} \leq\right.$ $\left.0, \mathrm{MKT}_{t-1}^{m}>0\right], E\left[\mathrm{SMB}_{t}^{m} \mid \mathrm{MKT}_{T-1}^{a}>0, \mathrm{MKT}_{t-1}^{m} \leq 0\right]$, and $E\left[\mathrm{SMB}_{t}^{m} \mid \mathrm{MKT}_{T-1}^{a}>0, \mathrm{MKT}_{t-1}^{m}>0\right]$.

As it might be expected, the mean monthly returns on the SMB factor are the highest conditional on both $\mathrm{MKT}_{T-1}^{a} \leq 0$ and $\mathrm{MKT}_{t-1}^{m}>0$. In addition, these mean monthly returns are statistically significantly different from all other corresponding conditional mean monthly returns. Obviously, the highest size premium tends to be generated during the months following the months in which the return on the market was positive given that the return on the market was negative during the preceding calendar year. The next highest size premium tends to be generated when both $\mathrm{MKT}_{T-1}^{a}>0$ and $\mathrm{MKT}_{t-1}^{m}>0$. Again, the $P$ values of the $t-$ statistics indicate that the mean monthly returns conditional on both $\mathrm{MKT}_{T-1}^{a}>0$ and $\mathrm{MKT}_{t-1}^{m}>0$ are statistically significantly different from all other corresponding conditional mean monthly returns. When it comes to the January mean return, it is the highest conditional on both $\mathrm{MKT}_{T-1}^{a} \leq 0$ 
TABLE 4: The mean monthly returns on the SMB factor conditional on the signs of both the market return during the preceding calendar year and the preceding month. The means are given in percents. The value in the brackets reports the $P$ value of the (two-tailed) $t$-test for zero mean. Bold text indicates values that are statistically significant at the $5 \%$ level.

\begin{tabular}{lcccc}
\hline & & \multicolumn{2}{c}{ Mean return conditional on } \\
Month(s) & $\mathrm{MKT}_{T-1}^{a} \leq 0$ & $\mathrm{MKT}_{T-1}^{a} \leq 0$ & $\mathrm{MKT}_{T-1}^{a}>0$ & $\mathrm{MKT}_{T-1}^{a}>0$ \\
& $\mathrm{MKT}_{t-1}^{m} \leq 0$ & $\mathrm{MKT}_{t-1}^{m}>0$ & $\mathbf{- 0 . 4 8}(0.02)$ & $\mathbf{0 . 4 0}(0.00)$ \\
\hline All together & $-0.40(0.23)$ & $\mathbf{1 . 7 6}(0.00)$ & $-\mathbf{0 . 5 4}(0.01)$ & $0.22(0.08)$ \\
Non-January & $-\mathbf{0 . 8 8}(0.01)$ & $\mathbf{1 . 6 6}(0.00)$ & $1.33(0.16)$ & $\mathbf{1 . 8 8}(0.00)$ \\
January & $\mathbf{4 . 7 0}(0.00)$ & $\mathbf{2 . 9 3}(0.01)$ & & \\
\hline
\end{tabular}

TABLE 5: The values of the $t$-statistics of the pairwise hypothesis test (two-sample two-tailed $t$-test) for equal mean monthly returns on the SMB factor conditional on the signs of both the market return during the preceding calendar year and the preceding month. The $P$ values are given in brackets. Bold text indicates values that are statistically significant at the $5 \%$ level.

\begin{tabular}{|c|c|c|c|c|}
\hline Conditional on & $\begin{array}{l}\mathrm{MKT}_{T-1}^{a} \leq 0 \\
\mathrm{MKT}_{t-1}^{m} \leq 0\end{array}$ & $\begin{array}{l}\mathrm{MKT}_{T-1}^{a} \leq 0 \\
\mathrm{MKT}_{t-1}^{m}>0\end{array}$ & $\begin{array}{l}\mathrm{MKT}_{T-1}^{a}>0 \\
\mathrm{MKT}_{t-1}^{m} \leq 0\end{array}$ & $\begin{array}{l}\mathrm{MKT}_{T-1}^{a}>0 \\
\mathrm{MKT}_{t-1}^{m}>0\end{array}$ \\
\hline \multicolumn{5}{|c|}{ All months together } \\
\hline $\mathrm{MKT}_{T-1}^{a} \leq 0, \mathrm{MKT}_{t-1}^{m} \leq 0$ & $0.00(1.00)$ & $-4.26(0.00)$ & $0.20(0.84)$ & $-2.26(0.03)$ \\
\hline $\mathrm{MKT}_{T-1}^{a} \leq 0, \mathrm{MKT}_{t-1}^{m}>0$ & $4.26(0.00)$ & $0.00(1.00)$ & $5.15(0.00)$ & $3.39(0.00)$ \\
\hline $\mathrm{MKT}_{T-1}^{a}>0, \mathrm{MKT}_{t-1}^{m} \leq 0$ & $-0.20(0.84)$ & $-5.15(0.00)$ & $0.00(1.00)$ & $-3.68(0.00)$ \\
\hline $\mathrm{MKT}_{T-1}^{a}>0, \mathrm{MKT}_{t-1}^{m}>0$ & $2.26(0.03)$ & $-\mathbf{3 . 3 9}(0.00)$ & $3.68(0.00)$ & $0.00(1.00)$ \\
\hline \multicolumn{5}{|c|}{ Non-January months } \\
\hline $\mathrm{MKT}_{T-1}^{a} \leq 0, \mathrm{MKT}_{t-1}^{m} \leq 0$ & $0.00(1.00)$ & $-4.96(0.00)$ & $-0.90(0.37)$ & $-3.29(0.00)$ \\
\hline $\mathrm{MKT}_{T-1}^{a} \leq 0, \mathrm{MKT}_{t-1}^{m}>0$ & $4.96(0.00)$ & $0.00(1.00)$ & $4.81(0.00)$ & $3.39(0.00)$ \\
\hline $\mathrm{MKT}_{T-1}^{a}>0, \mathrm{MKT}_{t-1}^{m} \leq 0$ & $0.90(0.37)$ & $-4.81(0.00)$ & $0.00(1.00)$ & $-3.14(0.00)$ \\
\hline $\mathrm{MKT}_{T-1}^{a}>0, \mathrm{MKT}_{t-1}^{m}>0$ & $3.29(0.00)$ & $-3.39(0.00)$ & $3.14(0.00)$ & $0.00(1.00)$ \\
\hline \multicolumn{5}{|c|}{ January months } \\
\hline $\mathrm{MKT}_{T-1}^{a} \leq 0, \mathrm{MKT}_{t-1}^{m} \leq 0$ & $0.00(1.00)$ & $1.19(0.25)$ & $2.38(0.03)$ & $2.36(0.04)$ \\
\hline $\mathrm{MKT}_{T-1}^{a} \leq 0, \mathrm{MKT}_{t-1}^{m}>0$ & $-1.19(0.25)$ & $0.00(1.00)$ & $1.21(0.24)$ & $0.97(0.35)$ \\
\hline $\mathrm{MKT}_{T-1}^{a}>0, \mathrm{MKT}_{t-1}^{m} \leq 0$ & $-2.38(0.03)$ & $-1.21(0.24)$ & $0.00(1.00)$ & $-0.56(0.58)$ \\
\hline $\mathrm{MKT}_{T-1}^{a}>0, \mathrm{MKT}_{t-1}^{m}>0$ & $-2.36(0.04)$ & $-0.97(0.35)$ & $0.56(0.58)$ & $0.00(1.00)$ \\
\hline
\end{tabular}

and $\mathrm{MKT}_{t-1}^{m} \leq 0$, yet it is not statistically significantly different from the second highest mean January return conditional on both $\mathrm{MKT}_{T-1}^{a} \leq 0$ and $\mathrm{MKT}_{t-1}^{m}>0$. In addition, the mean January return conditional on both $\mathrm{MKT}_{T-1}^{a} \leq 0$ and $\mathrm{MKT}_{t-1}^{m} \leq 0$ is statistically significantly different from mean January returns conditional on $\mathrm{MKT}_{T-1}^{a}>0$ regardless of the sign of the market return during the preceding month. This evidence suggests that the January effect tends to be stronger if during the preceding calendar year the stock market return was negative.

Finally note that the mean returns on the SMB factor conditional on $\mathrm{MKT}_{t-1}^{m} \leq 0$ for all months together and non-January months are virtually all statistically significantly negative regardless of the sign of the market return during the preceding calendar year. Besides, the mean returns on the $\mathrm{SMB}$ factor conditional on both $\mathrm{MKT}_{T-1}^{a} \leq 0$ and $\mathrm{MKT}_{t-1}^{m} \leq$ 0 are not statistically significantly different from the mean returns on the SMB factor conditional on both $\mathrm{MKT}_{T-1}^{a}>0$ and $\mathrm{MKT}_{t-1}^{m} \leq 0$ for all months together and non-January months. This evidence allows us to conclude that a negative size premium tends to be generated during the months following the months in which the return on the market was negative regardless of the sign of the market return during the preceding calendar year. Furthermore, a positive size premium tends to be generated during the months following the months in which the return on the market was positive. Yet, in this case, the magnitude of the size premium depends heavily on the sign of the market return during the preceding calendar year. Specifically, the size premium tends to be substantially higher when the return on the market during the preceding calendar year was negative.

\section{Building a Predictive Model}

4.1. January Effect. If we assume that the monthly returns on the SMB factor are independent and identically distributed random variables, this assumption would mean that the monthly returns conform to the following process:

$$
\mathrm{SMB}_{t}^{m}=\beta_{0}+\varepsilon_{t},
$$

where $\beta_{0}$ is the mean monthly return on the SMB factor and $\varepsilon_{t}$ is an i.i.d. random variable with zero mean. Accounting for the January effect requires introducing a dummy variable $\delta_{J}$ that takes the value 1 for every January and 0 for every other month. The model (3) transforms into

$$
\mathrm{SMB}_{t}^{m}=\beta_{0}+\delta_{J} \beta_{J}+\varepsilon_{t} \text {, }
$$


where $\beta_{0}$ is interpreted now as the mean return on the SMB factor in non-January months. In January months, the mean return on the SMB factor is given by $\beta_{0}+\beta_{J}$. The results of the estimation of models (3) and (4) are reported in Table 6 and agree with the results presented in Section 3.1. In brief, whereas in model (3) $\beta_{0}=0.25 \%$ and is statistically significant at the $2 \%$ level, in model (4) $\beta_{0}=0.07 \%$ and is insignificantly different from zero. On the other hand, $\beta_{J}=$ $2.23 \%$ and is highly statistically significant. Again, we are tempted to conclude that the size effect is almost entirely due to higher returns on small stocks in January.

\subsection{Dependence on the Market Return during the Preceding} Month. The evidence presented in Section 3.2 tells us that a monthly return on the SMB factor depends on the sign of the market return during the preceding month. In particular, the mean return on the SMB factor tends to be positive during the months following the months in which the return on the market was positive. In contrast, the mean return on the SMB factor tends to be negative during the months following the months in which the return on the market was negative. In addition, we know that the January effect persists regardless of the sign of the market return in December. The most straightforward manner to incorporate the dependence of the SMB factor return in month $t$ on the market return in month $t-1$ is by adding a term with $\mathrm{MKT}_{t-1}^{m}$ to model (4). The predictive regression for $\mathrm{SMB}_{t}^{m}$ becomes

$$
\mathrm{SMB}_{t}^{m}=\beta_{0}+\delta_{J} \beta_{J}+\beta_{1} \mathrm{MKT}_{t-1}^{m}+\varepsilon_{t},
$$

where $\beta_{1}$ is the slope parameter that can be interpreted as the sensitivity of the SMB factor return to the market return in the preceding month. Specifically, it is the amount by which the $\mathrm{SMB}$ factor return in month $t$ tends to increase or decrease for every $1 \%$ increase or decrease in the return on the market in month $t-1$.

Observe that in regression (5) $\mathrm{SMB}_{t}^{m}$ is a linear function of $\mathrm{MKT}_{t-1}^{m}$. That is, this regression assumes that the monthly SMB factor return responds symmetrically to both negative and positive returns on the market during the preceding month. Putting it in other words, the regression assumes that the SMB factor return exhibits a lagged and symmetrical reaction to both bad and good macroeconomic news. However, Mcqueen et al. [27] document a directional asymmetry in the lead-lag relationship between the returns on the large and small cap stocks. More specifically, these authors discover that the small stocks lag the large stocks in response to good news but not to bad news. This empirical fact motivates us to consider another alternative specification of the predictive regression for $\mathrm{SMB}_{t}^{m}$ by incorporating the directional asymmetry in the following manner:

$$
\begin{aligned}
\mathrm{SMB}_{t}^{m}= & \beta_{0}+\delta_{J} \beta_{J}+\beta_{1}^{\mathrm{DN}} \min \left(\mathrm{MKT}_{t-1}^{m}, 0\right) \\
& +\beta_{1}^{\mathrm{UP}} \max \left(\mathrm{MKT}_{t-1}^{m}, 0\right)+\varepsilon_{t} .
\end{aligned}
$$

This regression allows the slope parameter $\beta_{1}$ to differ when the market is up $\left(\mathrm{MKT}_{t-1}^{m}>0\right)$ or down $\left(\mathrm{MKT}_{t-1}^{m} \leq 0\right)$. The results of the estimation of regressions (5) and (6) are reported in Table 6.
In order to decide which model fits the data best, we use two model selection criteria: the adjusted $R^{2}$ and the Akaike Information Criterion (AIC, due to Akaike [33]). We remind the reader that the higher the adjusted $R^{2}$ and the lower the AIC, the better a model fits the data. Observe that according to both the model selection criteria the model with directional asymmetry fits the data better than the linear model. Consequently, our results on the asymmetric reaction of the SMB factor return to good and bad news agree very well with the findings of Mcqueen et al. [27]. When the monthly return on the market is positive, $\beta_{1}^{\mathrm{UP}}=0.32$ and is highly statistically significant. In contrast, when the monthly return on the market is negative, $\beta_{1}^{\mathrm{DN}}=-0.04$ and is not statistically significantly different from zero. Overall, model (6) implies that in non-January months following the months in which the return on the market was negative, the SMB factor return is negative and amounts to $\beta_{0}=-0.75 \%$. In January months in this case the SMB factor return is positive and amounts to $\beta_{0}+\beta_{J}=1.49 \%$. In addition, in the months following the months in which the return on the market was positive, the SMB factor return tends to increase by $0.32 \%$ for every $1 \%$ increase in the return on the market.

\subsubsection{Dependence on the Market Return during the Preceding} Calendar Year. First of all, the evidence presented in Section 3.2 tells us that the SMB factor return is higher during a year following a year in which the return on the market was negative. In order to account for this effect, we introduce a dummy variable $\delta_{A}$ that takes the value 1 if the return on the market during the preceding calendar year was negative and 0 otherwise. Secondly, we have the evidence that the January effect is larger after years with a negative return on the market than after years with a positive return on the market. This effect can be accounted for by a dummy variable that is a product of two dummy variables $\delta=\delta_{J} \delta_{A}$. This dummy variable takes the value of 1 for every January that follows immediately after a year with a negative return on the market and 0 for every other month. The resulting model is given by the following regression:

$$
\mathrm{SMB}_{t}^{m}=\beta_{0}+\delta_{J} \beta_{J}+\delta_{A} \beta_{A}+\delta_{J} \delta_{A} \beta_{J A}+\varepsilon_{t},
$$

where $\beta_{0}$ is interpreted as the mean return on the SMB factor in non-January months immediately after years with a positive return on the market. On the other hand, the mean return on the SMB factor in non-January months immediately after years with a negative return on the market is given by $\beta_{0}+\beta_{A}$. The mean return on the SMB factor in January months is given by either $\beta_{0}+\beta_{J}$ or by $\beta_{0}+\beta_{J}+\beta_{A}+\beta_{I A}$ depending on whether the return on the market during the preceding year was positive or negative, respectively.

The results of the estimation of regressions (7) are reported in Table 6 . Observe that $\beta_{J}$ and $\beta_{A}$ are highly statistically significant, whereas $\beta_{J A}$ is statistically significant at the $10 \%$ level. The results of the estimation of regression (7) agree very well with the results presented in Table 3. In particular, the mean return on the SMB factor in nonJanuary (January) months amounts to either $-0.08 \%$ or $0.49 \%(1.79 \%$ or $3.77 \%)$ depending on whether the return on 


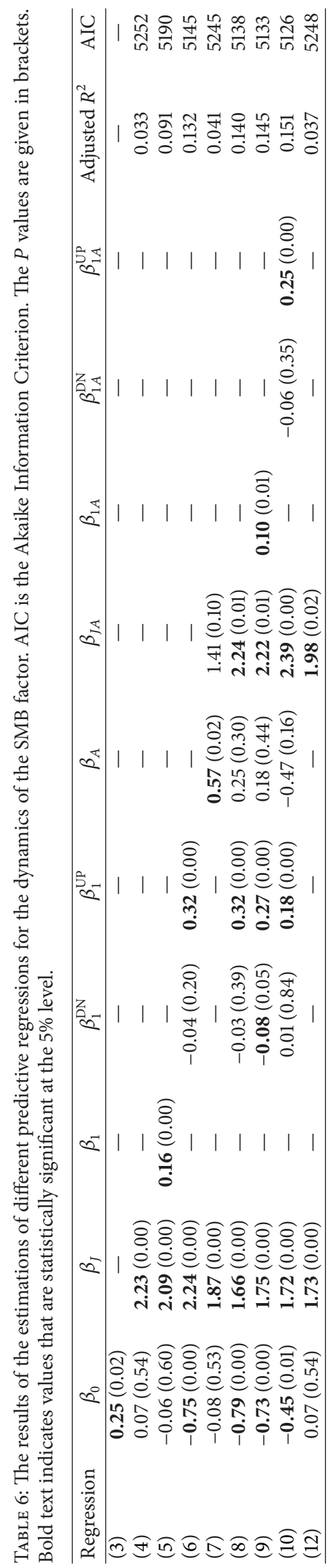


the market during the preceding year was positive or negative, respectively.

The last critical step is to build a predictive model for the SMB factor return that incorporates the dependence on both the market return during the preceding month and preceding calendar year. One straightforward alternative is to combine model (6) with model (7). This yields the following model:

$$
\begin{aligned}
\mathrm{SMB}_{t}^{m}= & \beta_{0}+\delta_{J} \beta_{J}+\beta_{1}^{\mathrm{DN}} \min \left(\mathrm{MKT}_{t-1}^{m}, 0\right) \\
& +\beta_{1}^{\mathrm{UP}} \max \left(\mathrm{MKT}_{t-1}^{m}, 0\right)+\delta_{A} \beta_{A}+\delta_{J} \delta_{A} \beta_{J A}+\varepsilon_{t} .
\end{aligned}
$$

The results of the estimation of regression (8) are also reported in Table 6 . Observe that in this model $\beta_{J A}$ is statistically significant at the $1 \%$ level, whereas $\beta_{A}$ is not statistically significantly different from zero. Putting it in words, the model is able to account for higher January returns after years with a negative return on the market but is not able to account for higher non-January returns. Besides, the evidence presented in Section 3.2 tells us that the non-January $\mathrm{SMB}$ factor returns conditional on both $\mathrm{MKT}_{T-1}^{a} \leq 0$ and $\mathrm{MKT}_{t-1}^{m}>0$ are statistically significantly higher than the nonJanuary SMB factor returns conditional on both $\mathrm{MKT}_{T-1}^{a}>0$ and $\mathrm{MKT}_{t-1}^{m}>0$. Apparently, the sensitivity of the SMB factor return to the market return during the preceding month depends heavily on the sign of the market return during the preceding calendar year. This says that the delayed reaction of the SMB factor return to good and bad news over a monthly horizon varies conditional on whether the stock market was up or down over the preceding calendar year. To incorporate this dependence we augment model (8) by adding additional reaction to good and bad news conditional on the sign of the market return during the preceding calendar year. Here we entertain two possibilities: symmetrical additional reaction that results in model (9) or, alternatively, asymmetrical additional reaction that results in model (10):

$$
\begin{aligned}
\mathrm{SMB}_{t}^{m}= & \beta_{0}+\delta_{J} \beta_{J}+\beta_{1}^{\mathrm{DN}} \min \left(\mathrm{MKT}_{t-1}^{m}, 0\right) \\
& +\beta_{1}^{\mathrm{UP}} \max \left(\mathrm{MKT}_{t-1}^{m}, 0\right)+\delta_{A} \beta_{A}+\delta_{J} \delta_{A} \beta_{J A} \\
& +\delta_{A} \beta_{1 A} \mathrm{MKT}_{t-1}^{m}+\varepsilon_{t}, \\
\mathrm{SMB}_{t}^{m}= & \beta_{0}+\delta_{J} \beta_{J}+\beta_{1}^{\mathrm{DN}} \min \left(\mathrm{MKT}_{t-1}^{m}, 0\right) \\
& +\beta_{1}^{\mathrm{UP}} \max \left(\mathrm{MKT}_{t-1}^{m}, 0\right)+\delta_{A} \beta_{A}+\delta_{J} \delta_{A} \beta_{J A} \\
& +\delta_{A} \beta_{1 A}^{\mathrm{DN}} \min \left(\mathrm{MKT}_{t-1}^{m}, 0\right)+\delta_{A} \beta_{1 A}^{\mathrm{UP}} \\
& \times \max \left(\mathrm{MKT}_{t-1}^{m}, 0\right)+\varepsilon_{t} .
\end{aligned}
$$

The results of the estimation of regressions (9) and (10) are again reported in Table 6 . Observe that according to both the model selection criteria model (10) fits the data better than model (9). Note that in model (10) both $\beta_{1}^{\mathrm{DN}}$ and $\beta_{1 A}^{\mathrm{DN}}$ are not statistically significant. This means that small stocks respond to bad news in a timely fashion regardless of the sign of the market return during the preceding calendar year.
In contrast, both $\beta_{1}^{\mathrm{UP}}$ and $\beta_{1 A}^{\mathrm{UP}}$ are highly statistically significant. Note that if the return on the market during the preceding calendar year was positive, then the coefficient in front of $\max \left(\mathrm{MKT}_{t-1}^{m}, 0\right)$ is given by $\beta_{1}^{\mathrm{UP}}$ only. On the other hand, if the return on the market during the preceding calendar year was negative, then the coefficient in front of $\max \left(\mathrm{MKT}_{t-1}^{m}, 0\right)$ is given by $\beta_{1}^{\mathrm{UP}}+\beta_{1 A}^{\mathrm{UP}}$. Observe that the coefficients $\beta_{1}^{\mathrm{UP}}=0.18$ and $\beta_{1 \mathrm{AP}}^{\mathrm{UP}}=0.25$ are of roughly the same magnitude which means that the delayed reaction to good news conditional on $\mathrm{MKT}_{T-1}^{a} \leq 0$ is approximately double as strong as that conditional on $\mathrm{MKT}_{T-1}^{a}>0$. Finally observe that $\beta_{A}$ is not statistically significant. This suggests that higher SMB factor returns during non-January months following a year in which the market was down are entirely due to a stronger reaction to good news.

At the end of this section, we perform a robustness test. For this purpose, we split the total sample 1928-2011 into two equal nonoverlapping subsamples: the first one is from 1928 to 1969 , and the second one is from 1970 to 2011 . This time we estimate the following regression:

$$
\begin{aligned}
\mathrm{SMB}_{t}^{m}= & \beta_{0}+\delta_{J} \beta_{J}+\beta_{1}^{\mathrm{UP}} \max \left(\mathrm{MKT}_{t-1}^{m}, 0\right) \\
& +\delta_{J} \delta_{A} \beta_{J A}+\delta_{A} \beta_{1 A}^{\mathrm{UP}} \max \left(\mathrm{MKT}_{t-1}^{m}, 0\right)+\varepsilon_{t},
\end{aligned}
$$

which is obtained from regression (10) by retaining only the terms that are statistically significant in the total sample. Table 7 reports the results of the estimation. Observe that in the total sample all coefficients are highly statistically significant. A negative return over a calendar year predicts stronger January effect and stronger reaction to good news. Yet this result does not hold for each subsample. Only over the first subsample the reaction to good news is significantly stronger. In particular, the coefficient $\beta_{1 A}^{\mathrm{UP}}$ is highly statistically significant and is of the same magnitude as $\beta_{1}^{\mathrm{UP}}$. When it comes to the coefficient $\beta_{J A}$, even though it is economically significant, it is not statistically significant at conventional statistical levels. In addition, over this subsample $\beta_{J A}<\beta_{J}$. By contrast, over the second subsample, the coefficient $\beta_{1 A}^{\mathrm{UP}}$ is not statistically significant (and probably not economically significant either), whereas the coefficient $\beta_{J A}$ is both highly economically and statistically significant. Over this subsample, this coefficient is almost double as high as $\beta_{J}$. We conclude that over the first subsample a higher size premium (during years following years with a negative return on the market) was generated mainly due to a stronger reaction to good news. In contrast, over the second subsample a higher size premium was generated due to a much stronger January effect. Finally observe that for the second subsample the predictive power of the model, as measured by the regression adjusted $R^{2}$, is notably less than for the first subsample. This might suggest that the predictability of the size premium has been diminishing through time. Putting it differently, this might indicate that the stock market efficiency has been increasing through time. 
TABLE 7: The results of the estimations of the predictive regression $\mathrm{SMB}_{t}^{m}=\beta_{0}+\delta_{J} \beta_{J}+\beta_{1}^{\mathrm{UP}} \max \left(\mathrm{MKT}_{t-1}^{m}, 0\right)+\delta_{J} \delta_{A} \beta_{J A}+$ $\delta_{A} \beta_{1 A}^{\mathrm{UP}} \max \left(\mathrm{MKT}_{t-1}^{m}, 0\right)+\varepsilon_{t}$ for different subperiods. The $P$ values of the estimated coefficients are given in brackets. Bold text indicates coefficients that are statistically significant at the $5 \%$ level.

\begin{tabular}{lcccccc}
\hline Period & $\beta_{0}$ & $\beta_{J}$ & $\beta_{1}^{\text {UP }}$ & $\beta_{J A}$ & $\beta_{1 A}^{\text {UP }}$ & Adjusted $R^{2}$ \\
\hline $1928-2011$ & $-\mathbf{0 . 6 1}(0.00)$ & $\mathbf{1 . 8 0}(0.00)$ & $\mathbf{0 . 2 2}(0.00)$ & $\mathbf{1 . 8 2}(0.02)$ & $\mathbf{0 . 1 6}(0.00)$ & 0.155 \\
$1928-1969$ & $-\mathbf{0 . 5 9}(0.00)$ & $\mathbf{2 . 4 0}(0.00)$ & $\mathbf{0 . 1 9}(0.00)$ & $1.52(0.17)$ & $\mathbf{0 . 2 1}(0.00)$ & 0.216 \\
$1970-2011$ & $-\mathbf{0 . 5 8}(0.00)$ & $\mathbf{1 . 1 9}(0.04)$ & $\mathbf{0 . 2 5}(0.00)$ & $\mathbf{2 . 1 3}(0.05)$ & $0.09(0.23)$ & 0.081 \\
\hline
\end{tabular}

TABLE 8: Mean returns on the SMB factor for all months together (denoted by $\mu_{\text {All }}$ ), non-January months (denoted by $\mu_{\text {non-Jan }}$ ), and January months. The mean returns are reported for all years, years with a positive return on the SMB factor, and years with a negative annual return on the SMB factor. The fraction $\left|\left(\mu_{\text {All }}-\mu_{\text {non-Jan }}\right) / \mu_{\text {All }}\right|$ helps to assess how much of the size effect can be attributed to the January effect. The means are given in percents. The value in the brackets reports the $P$ value of the (two-tailed) $t$-test for zero mean. Bold text indicates values that are statistically significant at the $5 \%$ level.

\begin{tabular}{lcccc}
\hline & & Months & & $\left|\left(\mu_{\text {All }}-\mu_{\text {non-Jan }}\right) / \mu_{\text {All }}\right|$ \\
\hline All years & All together & Non-January & January & 0.75 \\
Years with $\mathrm{SMB}_{T}^{a}>0$ & $\mathbf{0 . 2 5}(0.02)$ & $0.06(0.56)$ & $\mathbf{2 . 2 9}(0.00)$ & $\mathbf{3 . 4 2 ( 0 . 0 0 )}$ \\
Years with $\mathrm{SMB}_{T}^{a} \leq 0$ & $\mathbf{0 . 9 6}(0.00)$ & $\mathbf{0 . 7 3}(0.00)$ & $0.89(0.06)$ & 0.23 \\
\hline
\end{tabular}

\section{Reconsidering the Role of the January Effect}

It is widely believed that the size effect can, to a large extent, be attributed to the January effect. In this section, using two different approaches, we argue that the January effect constitutes a much lesser part of the size effect than it was previously suggested.

First of all, observe that model (10) implies that there are two sources of the predictive variation in the SMB factor return: the January effect and the delayed response to macroeconomic news. It is therefore possible to find out how much of the predictive variation in the SMB factor return can be attributed to the January effect and how much to the delayed response. To do this, we estimate a restricted version of model (10) which incorporates only the January effect:

$$
\mathrm{SMB}_{t}^{m}=\beta_{0}+\delta_{J} \beta_{J}+\delta_{J} \delta_{A} \beta_{J A}+\varepsilon_{t} .
$$

As before, Table 6 reports the results of the estimation of regression (12). Observe that model (12), that accounts only for the January effect, explains $3.7 \%$ of the predictive variation in the SMB factor return. On the other hand, model (10), that accounts for both the January effect and the delayed response, explains $15.1 \%$ of the predictive variation in the SMB factor return. That is, only $24.5 \%$ of the total predictive variation in the SMB factor return can be attributed to the January effect, whereas $75.5 \%$ of the predictive variation in the SMB factor return can be attributed to the delayed response to macroeconomic news. Thereby, our results agree very well with the findings of Hou and Moskowitz [10] who demonstrate a significant reduction in the size premium after adjusting returns for the delay.

Our second argument is based on the following observation. The reason for the spurious absence of the size effect during non-January months in unconditional returns is the cyclical variations in the size premium. In particular, if we focus on non-January returns only, the periods with a positive size premium tend to be counterbalanced by periods with a negative size premium. As a result, the average (unconditional) size premium during non-January months becomes small and statistically insignificant. The idea behind our second argument is to estimate the mean returns on the $S M B$ factor for all months together, non-January months, and January months during all years together, years with a positive annual return on the $S M B$ factor, and years with a negative annual return on the SMB factor. The results of these estimations are reported in Table 8. The first row in Table 8 (for all years together) recapitulates the results reported previously in Table 1 . These results tell us that the mean SMB factor return during all months together amounts to $\mu_{\mathrm{All}}=0.25 \%$, whereas the mean SMB factor return during non-January months amounts to $\mu_{\text {non-Jan }}=0.06 \%$. The fraction $f=\left|\left(\mu_{\text {All }}-\mu_{\text {non-Jan }}\right) / \mu_{\text {All }}\right|$ helps to assess how much of the size effect can be attributed to the January effect. This fraction measures the relative reduction in the mean SMB factor return when we exclude the January returns. If we use all years in our sample regardless of the sign of the annual SMB factor return, $f=0.75$. Therefore, we are tempted to jump to the conclusion that $75 \%$ of the size effect can be attributed to the January effect. However, the results in Table 8 suggest that if we focus only on years with either positive or negative annual SMB factor returns, then we discover that the January effect constitutes a rather small fraction of the size effect. For example, the mean SMB factor return during all months together in years with a positive return on the SMB factor amounts to $\mu_{\text {All }}=0.96 \%$. If we exclude the January months, then in this case the mean SMB factor return amounts to $\mu_{\text {non-Jan }}=0.73 \%$, which gives $f=0.23$. Consequently, during years with a positive return on the SMB factor only $23 \%$ of the size affect can be attributed to the January effect. Similarly, during years with a negative return on the SMB factor only $22 \%$ of the size affect can be attributed to the January effect. That is, on average only about $22.5 \%$ 
of the size affect can be attributed to the January effect. This estimate $(22.5 \%)$ is very close to the other estimate $(24.5 \%)$ obtained using the first argument.

\section{Conclusions}

The results of our study advocate that the size effect has no single explanation but can be rather attributed to two different sources: the delayed price response and the January effect. According to our estimates only about $23-24 \%$ of the size effect can be attributed to the January effect. This is a much smaller estimate than that obtained in the previous literature. The rest, about $76-76 \%$ of the size effect, can be attributed to the delayed price response. Summing up, we present evidence that supports the delayed price response hypothesis of Hou and Moskowitz [10] as well as the "taxloss selling" and "window dressing" hypotheses (as the most likely sources of the January effect). Our findings reveal that both the delayed price response and the January effect become much stronger if a period of adverse economic conditions lasts relatively long. This effect seems to confuse researchers by making them incorrectly conclude that the size premium is the investors' compensation for bearing a greater systematic risk. The same effect gave apparently rise to both the (il-)liquidity and survivorship bias hypotheses. This is because it is well documented that the stock market liquidity decreases in bad times of economy (see Næs et al. [34]) at the same time the number of delisted stocks increases. Thus, even though our findings do not support either the risk-based, (il)liquidity, or survivorship bias hypotheses, nevertheless we can explain why these hypotheses are being stated.

\section{Conflict of Interests}

The author declares that there is no conflict of interests regarding the publication of this paper.

\section{References}

[1] R. W. Banz, "The relationship between return and market value of common stocks," Journal of Financial Economics, vol. 9, no. 1, pp. 3-18, 1981.

[2] M. R. Reinganum, "Misspecification of capital asset pricing. Empirical anomalies based on earnings' yields and market values," Journal of Financial Economics, vol. 9, no. 1, pp. 19-46, 1981.

[3] K. C. Chan, N.-F. Chen, and D. A. Hsieh, "An exploratory investigation of the firm size effect," Journal of Financial Economics, vol. 14 , no. 3, pp. 451-471, 1985.

[4] E. F. Fama and K. R. French, "Common risk factors in the returns on stocks and bonds," Journal of Financial Economics, vol. 33, no. 1, pp. 3-56, 1993.

[5] M. Vassalou and Y. Xing, "Default risk in equity returns," Journal of Finance, vol. 59, no. 2, pp. 831-868, 2004.

[6] H. R. Stoll and R. E. Whaley, "Transaction costs and the small firm effect," Journal of Financial Economics, vol. 12, no. 1, pp. 5779, 1983.
[7] L. Pástor and R. F. Stambaugh, "Liquidity risk and expected stock returns," Journal of Political Economy, vol. 111, no. 3, pp. 642-685, 2003.

[8] S. P. Kothari, J. Shanken, and R. G. Sloan, "Another look at the cross-section of expected stock returns," Journal of Finance, vol. 50, no. 1, pp. 185-224, 1995.

[9] T. Shumway and V. A. Warther, "The delisting bias in CRSP's Nasdaq data and its implications for the size effect," Journal of Finance, vol. 54, no. 6, pp. 2361-2379, 1999.

[10] K. Hou and T. J. Moskowitz, "Market frictions, price delay, and the cross-section of expected returns," Review of Financial Studies, vol. 18, no. 3, pp. 981-1020, 2005.

[11] A. W. Lo and A. G. MacKinlay, "Data-snooping biases in tests of financial asset pricing models," Review of Financial Studies, vol. 3, no. 3, pp. 431-467, 1990.

[12] F. Black, "Beta and return," Journal of Portfolio Management, vol. 20, no. 1, pp. 8-18, 1993.

[13] D. B. Keim, "Size-related anomalies and stock return seasonality. Further empirical evidence," Journal of Financial Economics, vol. 12, no. 1, pp. 13-32, 1983.

[14] P. Brown, A. W. Kleidon, and T. A. Marsh, "New evidence on the nature of size-related anomalies in stock prices," Journal of Financial Economics, vol. 12, no. 1, pp. 33-56, 1983.

[15] C. G. Lamoureux and G. C. Sanger, "Firm size and turn-of-theyear effects in the OTC/NASDAQ market," Journal of Finance, vol. 44, no. 5, pp. 1219-1245, 1989.

[16] K. Daniel and S. Titman, "Evidence on the characteristics of cross sectional variation in stock returns," Journal of Finance, vol. 52, no. 1, pp. 1-33, 1997.

[17] M. A. van Dijk, "Is size dead? A review of the size effect in equity returns," Journal of Banking and Finance, vol. 35, no. 12, pp. 3263-3274, 2011.

[18] J. R. Ritter, "The buying and selling behavior of individual investors at the turn of the year," Journal of Finance, vol. 43, no. 3, pp. 701-719, 1988.

[19] V. R. Eleswarapu and M. R. Reinganum, "The seasonal behavior of the liquidity premium in asset pricing," Journal of Financial Economics, vol. 34, no. 3, pp. 373-386, 1993.

[20] I. D. Dichev, "Is the risk of bankruptcy a systematic risk?" Journal of Finance, vol. 53, no. 3, pp. 1131-1147, 1998.

[21] Y. Amihud, "Illiquidity and stock returns: cross-section and time-series effects," Journal of Financial Markets, vol. 5, no. 1, pp. 31-56, 2002.

[22] B. Malkiel, "The efficient market hypothesis and its," Journal of Economic Perspectives, vol. 17, no. 1, pp. 59-82, 2003.

[23] E. Dimson and P. Marsh, "Murphy's law and market anomalies," Journal of Portfolio Management, vol. 25, no. 2, pp. 53-69, 1999.

[24] M. Baker and J. Wurgler, "Investor sentiment and the crosssection of stock returns," Journal of Finance, vol. 61, no. 4, pp. 1645-1680, 2006.

[25] V. Zakamulin, "Forecasting the size premium over different time horizons," Journal of Banking and Finance, vol. 37, no. 3, pp. 1061-1072, 2013.

[26] C. S. Eun, W. Huang, and S. Lai, "International diversification with large- and small-cap stocks," Journal of Financial and Quantitative Analysis, vol. 43, no. 2, pp. 489-524, 2008.

[27] G. Mcqueen, M. Pinegar, and S. Thorley, "Delayed reaction to good news and the cross-autocorrelation of portfolio returns," Journal of Finance, vol. 51, no. 3, pp. 889-919, 1996. 
[28] I. Welch and A. Goyal, "A comprehensive look at the empirical performance of equity premium prediction," Review of Financial Studies, vol. 21, no. 4, pp. 1455-1508, 2008.

[29] A. W. Lo and A. G. MacKinlay, "When are contrarian profits due to stock market overreaction?" Review of Financial Studies, vol. 3, no. 2, pp. 175-205, 1990.

[30] W. E. Ferson and C. R. Harvey, "Conditioning variables and the cross section of stock returns," Journal of Finance, vol. 54, no. 4, pp. 1325-1360, 1999.

[31] M. Cooper, H. Gulen, and M. Vassalou, "Investing in size and book-to-market portfolios using information about the macroeconomy: some new trading rules," Working Paper, Graduate School of Business, Columbia University and Krannert Graduate School of Management, Purdue University, 2001.

[32] B. Efron, "Bootstrap methods: another look at the jackknife," Annals of Statistics, vol. 7, no. 1, pp. 1-26, 1979.

[33] H. Akaike, "New look at the statistical model identification," IEEE Transactions on Automatic Control, vol. 19, no. 6, pp. 716723, 1974.

[34] R. Næs, J. A. Skjeltorp, and B. A. Ødegaard, "Stock market liquidity and the business cycle," Journal of Finance, vol. 66, no. 1, pp. 139-176, 2011. 

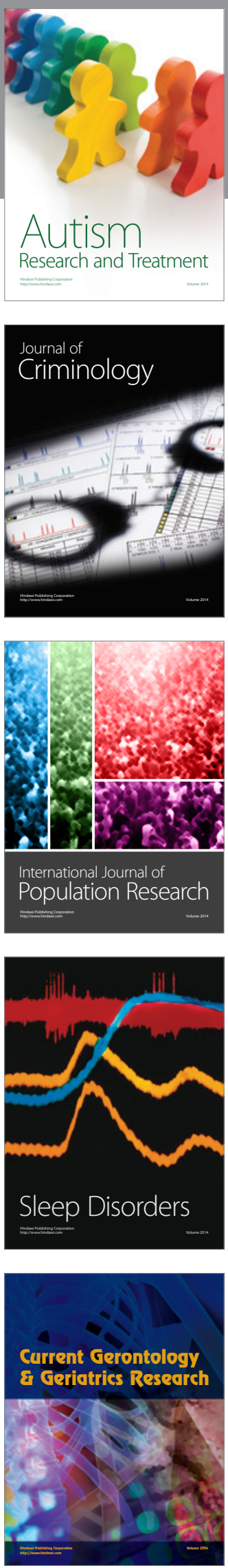
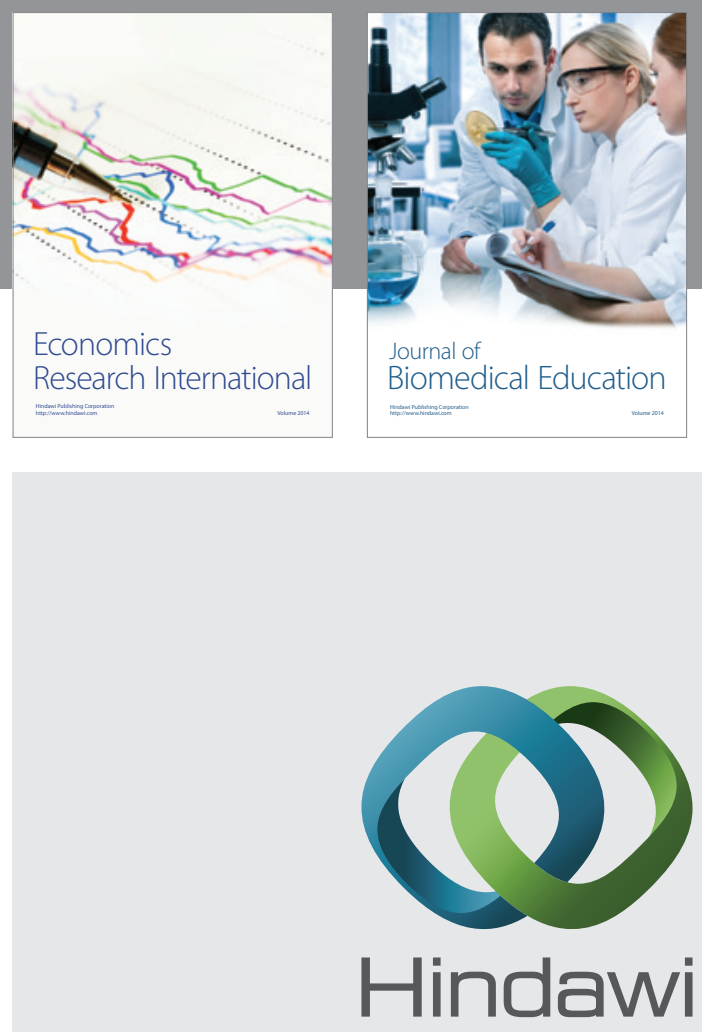

Submit your manuscripts at

http://www.hindawi.com
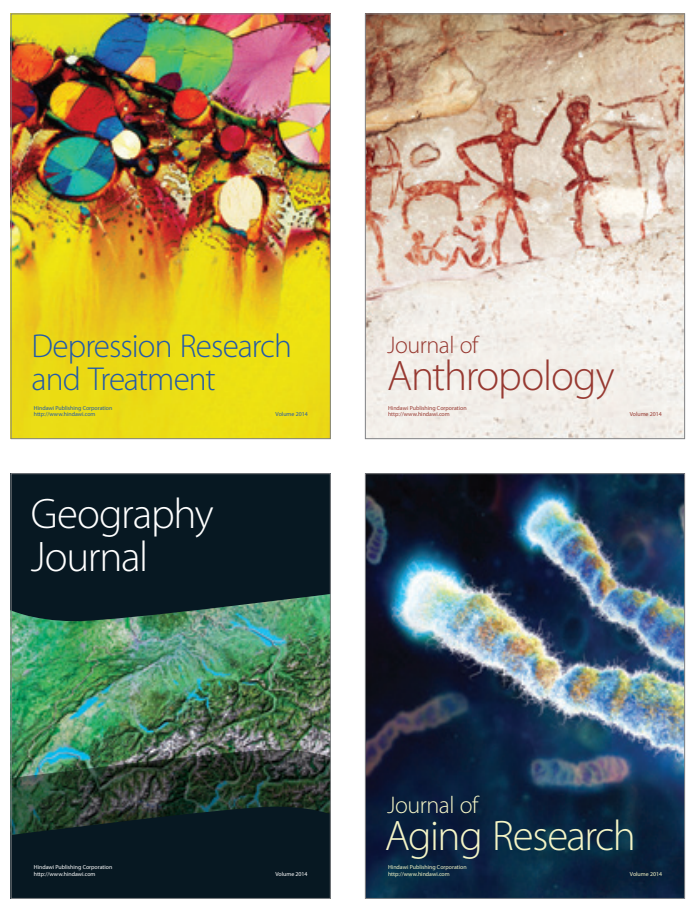
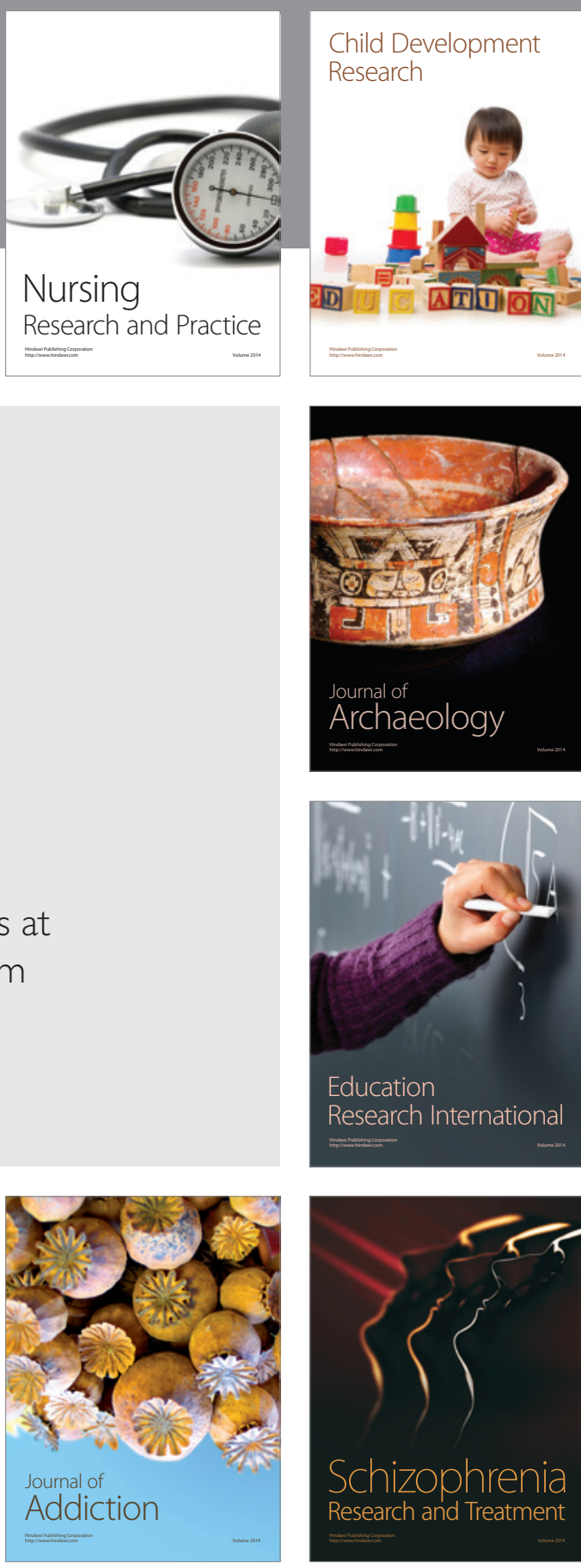

(D)
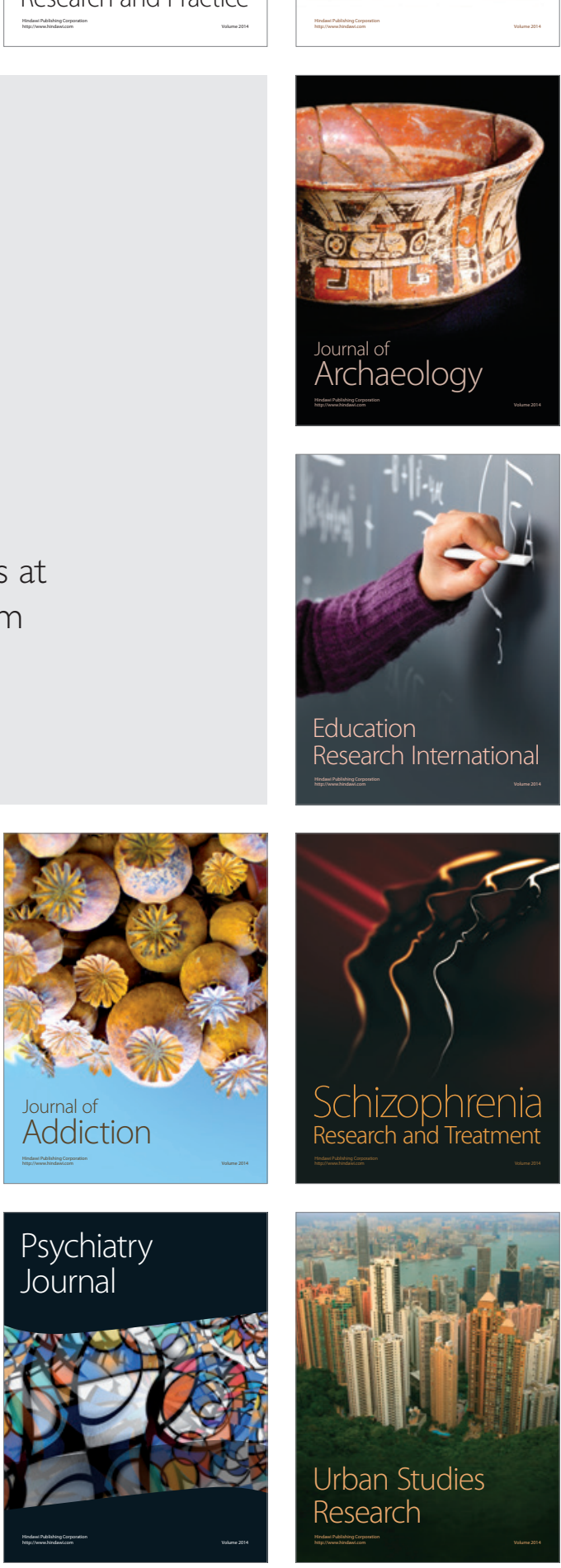